Cómo citar este artículo en Chicago: Calabrese, Claudio César y Ethel Beatriz Junco. "La exhortación a la vida filosófica en el diálogo de san Agustín Contra académicos”. Escritos 29, no. 63 (2021): 225-236. doi: http://doi.org/10.18566/escr.v29n63.a02

\title{
La exhortación a la vida filosófica en el diálogo de san Agustín Contra académicos
}

\author{
Exhortation to philosophical life in the dialogue Contra Academicos
}

\author{
Claudio César Calabrese ${ }^{1}$ \\ Ethel Beatriz Junco ${ }^{2}$
}

\begin{abstract}
RESUMEN
Este artículo tuvo por objetivo tratar el llamado agustiniano a la vida filosófica. En discusión con el escepticismo académico, san Agustín exhorta a su amigo Romaniano a la búsqueda de la sabiduría y, para ello, a desestimar igualmente la desconfianza y la confianza excesiva en la razón, pues argumenta tanto contra la postura escéptica, o desesperación de encontrar la verdad, como el dogmatismo o la seguridad de haber encontrado definitivamente la verdad. De hecho, san Agustín señala la dificultad de dar por cierto un conocimiento y, por ello, no descarta el escepticismo, sino que lo incorpora como la fase inicial del conocer y como antídoto contra la ingenuidad de dar a la facultad humana de conocer humano un alcance absoluto. En la perspectiva de este equilibrio, san Agustín exhorta a Romaniano a terminar de decidirse por llevar una vida filosófica. Para recorrer este camino, en continuidad con sus lecturas neoplatónicas, considera la belleza como guía: se accede a la belleza espiritual transitando por la cósmica; el alma que contempla, en tanto se corresponde con lo contemplado, puede alcanzar así el camino ascensional de su propia transformación. El método de acceso a los textos es filológico, es decir, que busca al mismo tiempo descifrar la letra de la trama filosófica y establecer una comprensión contextual de aquella. Un método de esta naturaleza es inseparable del marco conceptual; en efecto, la formación de un saber filosófico, que intenta encontrar los límites de la comprensión de la revelación, pone en tensión de perfección a la persona, es decir, la guía hacia su propia trascendencia.
\end{abstract}

Palabras clave: San Agustín; Escritos de juventud; Diálogos; Escepticismo; Neoplatonismo; Conversión; Vida filosófica; Contra Académicos.

1 Doctor en Letras por la Universidad del Salvador, Argentina y Doctor en Filosofía por la Universidad de Barcelona, España. Profesor-investigador del Departamento de Humanidades de la Universidad Panamericana, México. Correo electrónico: ccalabrese@up.edu.mx

2 Doctora en Letras por la Universidad del Salvador, Argentina y Doctora en Filosofía por la Universidad Autónoma de Barcelona, España. Profesora-investigadora de tiempo completo del Departamento de Humanidades de la Universidad Panamericana, México. Correo electrónico: ejunco@up.edu.mx 


\begin{abstract}
The objective of this article was to address the Augustinian call to philosophical life. In discussion with academic skepticism, Saint Augustine exhorts his friend Romanian to search for wisdom and, for this, to also dismiss distrust and excessive confidence in reason, since he argues both against the skeptical position, or despair of finding the truth, and dogmatism or the assurance of having definitely found the truth. In fact, Saint Augustine points out the difficulty of taking knowledge for granted and, therefore, does not rule out skepticism, but rather incorporates it as the initial phase of knowing and as an antidote to the naivety of giving absolute scope to the human faculty of human knowing. In the perspective of this balance, Saint Augustine exhorts Romanian to finish deciding to lead a philosophical life. To travel this path, in continuity with his Neoplatonic readings, he considers beauty as a guide: spiritual beauty is accessed by passing through the cosmic; the contemplating soul, insofar as it corresponds to what is contemplated, can thus reach the ascending path of its own transformation. The method of accessing the texts is philological, that is, it seeks at the same time to decipher the letter of the philosophical plot and to establish a contextual understanding of it. A method of this nature is inseparable from the conceptual framework; indeed, the formation of a philosophical knowledge, which tries to find the limits of the understanding of revelation, puts the person in tension of perfection, that is, it guides them towards their own transcendence.
\end{abstract}

Keywords: Saint Augustine; Youth writings; Dialogues; Skepticism; Neoplatonism; Conversion; Philosophical life; Contra Academicos.

\title{
Introducción
}

$\mathrm{S}$ an Agustín concibió sus obras en forma de diálogos entre 386 y 395-396, es decir, en la década que corrió entre el abandono de la docencia en Milán y su ordenación como obispo coadjutor de la diócesis de Hipona. En este marco temporal, se inscribe la estancia en Casiciaco, durante la cual redactó Contra los académicos (también mencionada en retr. 1,1 como De academicis), De beata vita, De ordine, Soliloquia y una primera versión de De immortalitate animae; todas estas obras son anteriores a su bautismo, que tuvo lugar en la Vigilia Pascual entre el 24 y el 25 de abril del 387, cuya ceremonia ofició san Ambrosio (ep. 36, 32). En Milán, de regreso de Casiciaco, san Agustín completó La inmortalidad del alma (retr, 1,1); entre el otoño de 387 y la primavera de 388 (quant. anim. I, 8, 7), mientras esperaba embarcarse de regreso a África, permaneció en Roma y escribió De quantitate animae y el libro I de De libero arbitrio. ${ }^{3}$ Ya establecido en África, compuso De musica, cuyas ideas germinales habían surgido en la estancia antes mencionada en Milán, y De Magistro. Son los años de juventud de san Agustín, en los que está dedicado tanto a la reflexión filosófica como a la frecuentación de las Escrituras y aún no se encuentra absorbido por las preocupaciones de su ministerio sacerdotal. Los diálogos no son, sin embargo, las únicas obras de este periodo, pues, entre otras, tenemos presente De Moribus ecclesiae catholicae: et de moribus manichaeorum (época romana, retr. 1, 1), De genesi contra Manichaeos y De vera religione (ambos escritos en África), las primeras cartas (1-20) y muchas de las primeras cuestiones (acaso cincuenta) que más tarde integrará en De diversis quaestionibus octoginta tribus. ${ }^{4}$ Voss $^{5}$ introdujo una distinción de importancia entre los diálogos: por un lado, los "escénicos" o "narrativos", en los que hay una dedicatoria, un prólogo y una reconstrucción de las discusiones sostenidas, a partir de las notas que tomaba uno de los miembros que no participaba activamente; por otro lado, los diálogos no escénicos se limitan a la superposición de los discursos de los

3 Othmar Perler, Les voyages de saint Augustin (París: Études Augustiniennes, 1969), 164-165.

4 José Anoz, “Cronología de la producción agustiniana”, Augustinus 47, n. ${ }^{\circ}$ 186-187 (2002): 240.

5 Bernd Reiner Voss, Der Dialog in der frühchristlichen Literatur (Múnich: Wilhelm Fink Verlag, 1970), 197 y ss. 
dos únicos interlocutores que participaban; Contra los académicos se encuentra dentro del primer grupo. Como sostuvimos, los diálogos no son las únicas obras, pero sí las más importantes de su primera etapa como escritor, hasta el punto de que, si su producción se hubiese detenido aquí, le hubiese asegurado un lugar relevante en la historia del pensamiento. ${ }^{6}$

Debemos considerar ahora las razones de la elección del género diálogo por parte de san Agustín, en especial porque luego lo reemplazará por el comentario de textos bíblicos y por la redacción de tratados. En principio, este género literario-filosófico está íntimamente ligado a los ideales de la época de Casiciaco; hay, en principio, una profunda tradición que se enraíza en Platón y culmina, para el Hiponense, en el texto que orientó su vida a buscar la sabiduría: el Hortensio, de Cicerón. Si bien la relación entre ambos suele plantearse casi exclusivamente desde esta perspectiva, debemos considerar que el camino hacia la sabiduría que comienza con esta lectura tiene múltiples idas y venidas, destacándose dos de aquellas: el maniqueísmo y el escepticismo. Una lectura, sin embargo, da luz para superar de una vez ambas situaciones: el encuentro con los libros de los platónicos, gracias a los cuales Agustín abandona el materialismo maniqueo y encuentra la disposición adecuada para tratar aquellos problemas que la lectura del Hortensius había suscitado, los cuales hallarán concreción en Casiciaco; es importante considerar que, entre las lecturas de este tiempo de retiro, estaban los Libri platonicorum, Virgilio y, sin duda, Cicerón, su gran maestro a la par del Mantuano. ${ }^{7}$

Con ello, queremos significar que la conversación y el diálogo eran el nervio de aquel tiempo de ocio, en la alquería que había facilitado su colega Verecundo, dispuesto como preparación bautismal. ${ }^{8}$ En este sentido, podemos afirmar que durante aquellos pocos meses hubo un retiro: un sitio relativamente aislado y un cierto tipo de "ejercicio espiritual", es decir, el desarrollo de una actitud existencial en la que se funda la construcción teórica; la filosofía clásica, a la que san Agustín se adhiere bajo la denominación compleja de neoplatonismo, es fundamentalmente un modo de vida y aquello que se alcanza mediante el "vivir bien" es la sabiduría; no es un camino que pueda ser recorrido individualmente, sino en comunidad. ${ }^{9}$ Esto es lo que lo lleva a abandonar la enseñanza de la retórica y a dedicarse a la "filosofía", a conocer "al alma y a Dios" (sol. 1, 7; ord. 2, 47), lo cual requería disciplina intelectual y rigor moral, otorgando al studium un sentido, a la vez, pedagógico y formativo. ${ }^{10}$ Por ello, a partir del antecedente platónico, desempeña un papel decisivo en los diálogos la convicción agustiniana de que la verdad mora en el interior de quien la busca (sol. 2, 35; imm. an. 4, 6). Según este modelo, tan ligado a las teorías socráticoplatónicas que identifican saber y recordar, el alumno no aprende del maestro, sino aleccionado por la verdad interior (mag. 14, 45); adecuadamente preguntado, el alumno puede ser iluminado por el Maestro interior para poder llegar al conocimiento.

La filosofía cristiana, que alcanza un significativo estado de madurez en la semántica latina de san Agustín, es entendida normalmente por las relaciones más o menos problemáticas que, en su seno, los filósofos o los teólogos establecen entre fe y razón o entre teología y filosofía; se ha fijado, de hecho, una sinonimia entre estos

6 Giovanni Catapano, introducción a Tutti i dialoghi, de san Agustín (Milán: Bompiani, 2019), XI.

7 Biviana Unger Parra, “Agustín y Cicerón: La búsqueda de la verdad”, Universitas Philosophica 33, n. ${ }^{\circ} 67$ (2016): 201215, https://doi.org/10.11144/Javeriana.uph33-67.acbv.

8 Voss, Der Dialog, 13-15.

9 Pierre Hadot, Exercices spirituels et philosophie antique (París: Éditions Albin Michel, 2003) 64 
binomios, aunque el segundo no resulta completamente correcto, porque algunas escuelas, comola platónica, la aristotélica y sus respectivas tradiciones, ofrecen una teología como culminación de su filosofía. ${ }^{11}$ Sin embargo, el trasfondo de esta distinción, de manera independiente de cómo se la entienda, es de origen medieval y más específicamente tomista, ${ }^{12}$ e intenta repensar, desde la raíz, la filosofía tal como había sido recibida de los antiguos. Obviamente no encontramos esto ni en la Antigüedad Tardía ni en la Temprana Edad Media, razón por la cual los pensadores de aquellas épocas no tuvieron necesidad de distinguir entre estas nociones: ellos pensaron desde el punto de vista de problemas, es decir, de preguntas, y no primariamente de soluciones, cuyo modelo es, en lo esencial, el diálogo socrático. Por esta razón, san Agustín no se planteó la continuidad con la filosofía o, de manera más general, con la cultura grecolatina, porque su vida simplemente estaba inmersa en ella. La definición clásica de sabiduría (sapientia) como conocimiento de las cosas humanas y divinas (rerum humanarum et divinarum) muestra un interés filosófico por lo divino, que no reclama la necesidad de iniciar una reflexión, aun en el contexto de los diálogos, sobre las relaciones entre razón y revelación, con el sentido que estas adquirirán, a la luz del credere ut intelligas. ${ }^{13}$ Por ello, consideramos que san Agustín durante este breve pero intenso proceso, que va desde el encuentro maduro con la filosofía neoplatónica en Milán hasta su ordenación episcopal, desarrolló una obra que encontró en el diálogo su instrumento natural (no en vano no volverá sobre este género literario-filosófico) y que forjó un nuevo modelo de racionalidad, el cual entrará en juego en la interpretación de las Escrituras, como será evidente, por sus alcances filosóficos y teológicos, ya en De Genesi adversus manichaeos, escrito hacia 388-389, es decir, antes de su ordenación sacerdotal.

\section{Contra los académicos}

Por la naturaleza de nuestro tema, no nos ocuparemos de una descripción detallada del diálogo, sino de las dos exhortaciones a la vida filosófica que encontramos en Contra los académicos, en sendas dedicatorias a Romaniano, en las aperturas de los libros I y II. La visión retrospectiva de Retractationes $(1,1)$ recrea la situación intelectual y espiritual del joven profesor, recientemente convertido y aún no bautizado, en que nos señala, en primer término, su abandono de la pompa del mundo (in cupiditatibus huius mundi) y su refugio en la paz de la vida cristiana (ad christianae vitae otium); una de las obras que comienza a escribir en esta época de paz u ocio es Contra los académicos, con la intención declarada de superar la parálisis provocada por los argumentos del escepticismo académico, que inoculan la desconfianza de encontrar la verdad y que, por ello, impiden dar asentimiento como verdadero a lo que encuentra el que busca. En otro punto de interés, observamos cómo el anciano obispo toma distancia del joven profesor impregnado de cultura clásica y se arrepiente de haber mencionado tantas veces el término fortuna $(1,1 ; 1,25 ; 2,1 ; 2$, $4 ; 2,9 ; 3,2-4)$, aunque no siempre se refiere a la deidad, sino, por lo común, a un acontecimiento fortuito

11 Alain de Libera, Albert le Grand et la philosophie (París: J. Vrin, 1990), 155.

12 Edward Grant, "Science and Theology in the Middle Ages", en God and Nature: Historical Essays on the Encounter between Christianity and Science. Ed. por David C. Lindberg y Ronald Numbers (Berkeley: University of California Press, 1986), 70; José María Felipe Mendoza, “Tomás de Aquino y la relación entre filosofía y teología: Una interpretación literal de la Suma de Teología I, Q. 1, Art. 1., Universitas Philosophica 35, n. ${ }^{\circ} 70$ (2018): 131-149; MarieDominique Goutierre, "La importancia del fin, causa de las causas: Hacia una teología viva y contemplativa en la escuela de santo Tomás”, Scripta Theologica 41, n. 2 (2009): 351-375.

13 Johannes Brachtendorf, "Augustinus und der philosophische Weisheitsbegriff”, en Die christlich-philosophischen Diskurse der Spätantike: Texte, Personen, Institutionen, ed. por Therese Fuhrer (Stuttgart: Franz Steiner Verlag, 2008), 261-274. 
que afecta de manera positiva o negativa. ${ }^{14} \mathrm{El}$ título de la obra, Contra los académicos, la primera que compuso en Casiciaco (ret. 1, 1), nos hace pensar que tiene un designio fundamentalmente polémico: argumentos dirigidos a descalificar la postura de la Academia Nueva o escéptica de Arcesilao y Carnéades; esta es la postura que todavía tiene en mente el anciano obispo cuando en Retractaciones $(1,1)$ señala que buscaba remover de su ánimo las vallas que esta filosofía había levantado en su ánimo contra la efectiva búsqueda de la verdad, luego de la crisis que significó la ruptura con el maniqueísmo. ¿Qué escepticismo, entonces? Sin duda aquel que niega la posibilidad de encontrar la verdad, aquella en la que puso tantos desvelos desde la lectura del Hortensius, siguiendo en buena medida la senda ciceroniana. Para Cicerón, y por extensión para san Agustín, la filosofía "en cuanto inquisitio veri es una empresa intelectual y existencial, que requiere una fuerte motivación interior, motivación que el escepticismo académico, en la medida en que conduce a la desperatio veri, podría destruir". ${ }^{15}$

El título no hace justicia a los complejos argumentos que se desarrollan, aunque tengamos presentes todas estas nociones. Esto es así, en principio, porque la discusión antiacadémica solo ocupa los dos últimos libros, que tienen una fisonomía intelectual completamente diversa del primero. ${ }^{16}$ En el núcleo de la polémica, por otra parte, los ataques están más bien dirigidos contra el materialismo estoico, y lo que parece más decisivo, las tesis propiamente escépticas, son incorporadas al filosofar en dos sentidos: la duda, por un lado, es el inicio de la apertura al filosofar y, por otro, resulta el antídoto contra la seguridad de haber encontrado una respuesta filosófica definitiva, que constituye una actitud tan nociva como aquella que da por seguro que no es posible hallar la verdad. Por ello, cuando en Retractaciones $(1,1)$ san Agustín se refiere a la obra, emplea por lo común el doble título Contra academicos vel de acadamicis.

\section{¿Quién fue Romaniano?}

Romaniano fue un patronus de Tagaste (conf. 6, 24), no mucho mayor que Agustín (ep. 27) y sí muy rico (conf. 6, 24). Los dos pasajes que presentamos nos ubican ante un hombre que ha realizado una carrera municipal, en la que alcanzó todos los honores: fue un sacerdotalis provincial, patrón de la ciudad, flamen perpetuo y posiblemente curator reipublicae y duunviro. Al parecer, se preocupaba por beneficiar a jóvenes estudiantes como Agustín, con el cual, además, estaba emparentado (ep. 26, 6). ${ }^{17}$ Gracias a él, a causa de la pronta muerte de su padre Patricio, san Agustín pudo continuar sus estudios en Cartago (acad. 2, 3), donde ingresó a la secta maniquea y ello provocó que, al volver a Tagaste en 374 para enseñar gramática, no fuese recibido por su madre (conf. 3, 19). Esta situación lo acercó aún más a Romaniano. En aquellos momentos, el rico tagastino, que ya simpatizaba con las ideas de Mani, fue definitivamente

14 Fortuna, cuando no significa acontecimiento inesperado de signo positivo o negativo, entra en sinonimia con Providencia, de ahí las lamentaciones del anciano obispo por su uso, al volver sobre el texto $($ retr. 1,1$)$ cuarenta años más tarde.

15 Giovanni Catapano, “Quale scetticismo viene criticato da Agostino nel Contra Academicos?”, Quaestio 6 (2006): 1-13; Michael P. Foley, "Cicero, Augustine, and the Philosophical Roots of the Cassiciacum Dialogues”, Revue d'Etudes Augustiniennes et Patristiques 45, n. 1 (1999): 51-77.

16 Claudio Moreschini, Storia del pensiero cristiano tardo-antico (Milán: Bompiani, 2013), 965-966.

17 Francesc Navarro Coma, "Amistad e intereses entre un curial rico y un curial pobre", Polis: Revista de Ideas y Formas Políticas de la Antigüedad Clásica 10 (1998): 247-267. 
convencido por el carismático profesor de retórica, lo que significó un gran crecimiento de partidarios de las doctrinas de Mani en Tagaste y alrededores. ${ }^{18}$ Durante estos años, previos a que san Agustín y su familia partieran de Cartago a Roma, ambos mantuvieron una estrecha relación; cuando se instalaron en Roma, el vínculo pierde lógicamente trato asiduo. Una vez en Milán, san Agustín obtuvo la cátedra pública de retórica y pasó a desempeñarse como retor oficial de la corte, es decir, se encontraba en una situación de privilegio en el contexto de la política cortesana, gracias a que había sido presentado por los maniqueos al prefecto Símaco (conf. 5, 23). ${ }^{19}$ Retomaron su relación cuando Romaniano sufrió un revés judicial en Cartago, que afectaba seriamente su patrimonio; esto lo llevó a apelar, luego de dos sentencias adversas del procónsul de África, a Milán, ciudad a la que se había trasladado la capital del Imperio de Occidente. No sabemos exactamente cuál fue la situación, porque san Agustín es muy parco en las obras en las que hace alguna mención de ello (Confessiones y Contra academicos). Sí queda claro que san Agustín tuvo oportunidad de regresar los favores recibidos, pues puso a su disposición su fuerte presencia en la corte, aunque no sabemos cómo terminó el embrollo legal.

\section{La dedicatoria del libro I $(1,1-3)$}

Como escribimos poco más arriba, la situación judicial de Romaniano era claramente adversa en la época de Casiciaco; esta realidad nos permite imaginarlo turbado en su ánimo. Así, entendemos el ruego inicial $(O$ utinam 1,1$)$ para que la fortaleza (virtus) lo sostenga en estas adversidades que lo mantienen completamente aislado en la esfera de los negocios y le impide volver a sí mismo y, entonces, a sus amigos. San Agustín insiste, en el carácter negativo y ciertamente abrumador de este contexto, que afectaba la excelente disposición para la vida filosófica de Romaniano (hominem sibi aptum); por ello, con una metáfora de la navegación, san Agustín afirma que nadie lo puede poner en movimiento hacia la sabiduría, si él mismo no toma la decisión de buscar buen puerto. $\mathrm{O}$ bien que las condiciones adversas estuvieran dispuestas por la Providencia (comparatum est), o bien a causa de los méritos (resulta un uso irónico del término, ya que el contexto hace referencia a la idea de culpa), o por disposición de la naturaleza humana.

Esto último conduce a la concepción dualista de la tradición platónica, pues san Agustín plantea una unión entre un alma divina, es decir, inmortal y un cuerpo mortal; esta deficiencia antropológica que plantea una unión necesariamente accidental impide que pueda ser auxiliada, a menos que ella misma decida dirigirse al puerto de la sabiduría, que se encuentra protegido de los vientos de la fortuna. La expresión latina para designar en compuesto es divinum animum mortalibus inhaerentem, es decir, "al alma divina ligada a las cosas mortales" $(1,1)$. El verbo intransitivo inhaereo tiene el significado básico de "permanece ligado o fijo a" y en sentido figurado "tener como o ser inseparable", y de ahí nuestro uso de "inherente". ${ }^{20}$ El verbo inhaereo, entonces, expresa el campo semántico de aquellas realidades diversas que se encuentran superpuestas durante un determinado lapso: el alma divina, inmortal, unida a "partes mortales" (mortalibus).

18 François Decret, Aspects du manichéisme dans l'Afrique romaine: Les controverses de Fortunatus, Faustus et Felix avec saint Augustin (París: Études augustiniennes et CNRS, 1970), 66.

19 Peter Brown, Augustine of Hippo: A Biography (Berkeley: University of California Press, 2000), 109-110.

20 Felix Gaffiot, Dictionnaire latin-français (París: Hachette, 1934), 820; Alfred Ernout y François Thomas, Syntaxe latine (París: Éditions Klincksieck, 1964), 12-14; Mariano Bassols de Climent, Sintaxis histórica de la lengua latina (Madrid: Consejo Superior de Investigaciones Científicas, 1948), 115-117, 198-202. 
La primera referencia al alma, entonces, parte de la idea de yuxtaposición de elementos separados por la antítesis inmortalidad/mortalidad. En tanto obra temprana de san Agustín, resulta conveniente hacer una anotación breve sobre el sentido de dos términos fundamentales: anima y animus. En principio, conviene precisar que su terminología no es unívoca, aunque anima tiende a la significación general de "principio vital de un cuerpo", según el cual los seres vivientes, en el sentido más amplio, son tales en tanto poseen un alma; animus, en general, expresa el principio mencionado como sustancia racional.

Recién años más tarde, en De civitate Dei (VII, 23), a partir del De diis selectis, de Varrón, el Hiponense afirmará la existencia de tres grados del alma o anima en el conjunto de la naturaleza: a) principio vital (ad vivendum valetudinem), tal como indicamos más arriba; b) la percepción sensible (in quo sensus est); c) la parte más elevada del alma (gradum animae esse summum), en la que descuella la inteligencia. Como Varrón, y tal vez por su influencia directa, san Agustín llamó a esta parte más elevada animus. En De civitate Dei $\mathrm{X}, 3$, leemos que esta última acepción no se distingue de mens, en referencia a las distintas vías que posee el ser humano para conocer lo real. Animus o mens, entonces, es la parte superior del alma que conoce los inteligibles y a Dios. Ratio ("razón") es el movimiento mediante el cual el alma pasa de un conocimiento a otro por la distinción y la asociación (De ordine 2,30 ).

En el contexto de Acad. 1, 1, le corresponde al alma la responsabilidad de iniciar el proceso ("ponerse en movimiento") y, por necesidad, llevar al cuerpo consigo; el compuesto no puede ser conducido o estimulado desde afuera: el alma debe tomar este empeño como propio y luego, en comunidad (los amigos que esperan en Casiciaco), encaminarse al puerto de la sabiduría. Por ello, san Agustín considera que solo puede dirigir a Dios, que tiene bajo su cuidado estas cosas (haec curae), los buenos deseos (vota), para que el alma divina de Romaniano pueda ponerse de camino. Estos vota también están coordinados con una segunda metáfora referida también a las vicisitudes náuticas: que el alma, que está ahogándose (Acad. 1, 1: quae respirationem iamdiu parturit), pueda alcanzar a respirar nuevamente, es decir, que emerja al aire fresco (in auras) de la verdadera libertad. El estado de incertidumbre o de peligro de estar ahogándose se debe a la imposibilidad humana de conocer el orden oculto de las cosas o Providencia, es decir, por qué acontecen cosas buenas o malas en la vida, "pues nada hay que no tenga congruencia con el universo" (Acad. 1, 1: nihilque seu commodi seu incommodi contingit in parte, quod non conveniat et congruat universo).

¿A qué filosofía es llamado Romaniano? "La filosofía a la que te invito promete mostrar a sus verdaderos amantes tal concepto (sententiam), velado en los oráculos de fecundísimas doctrinas, inaccesible y muy alejada de las inteligencias de los profanos" (Acad. 1, 1). Surgen dos preguntas: ¿cuál es la sententia o saber prometido por la filosofía? y ¿cuáles oráculos, velados a la inteligencia de los profanos, serán develados por la filosofía? En el primer caso, si referimos la promesa de saber a la metáfora náutica, que nos remonta a Cicerón (Tusc. V.3), parece significar que por filosofía debemos entender el aprendizaje que el alma necesita para conocerse a sí misma, y así dirigir su rumbo a buen puerto; por esta razón, si vinculamos esta promesa con las afirmaciones que siguen, la interacción entre el alma y la filosofía se matizan y profundizan: la filosofía no se considera solo un conjunto de conocimientos, sino fundamentalmente un modo de vida, es decir, un camino de comprensión de los designios de la Providencia, pues "hace contigo lo que conviene que se haga" (acad. 1, 1: sic tecum agi oportet, ut agitur). ${ }^{21}$

21 Giovanni Catapano, L’idea di filosofia in Agostino (Padua: Il Poligrafo, 2000), 98-99. 
Los problemas que acechan a Romaniano, que, si bien no están especificados, parecen afectar gravemente su patrimonio, lo han hecho consciente de su fragilidad y, entonces, de la necesidad de encontrar el camino hacia sí mismo. En el segundo caso, tal vez sea posible identificar "los oráculos de fertilísima doctrina" como una referencia general a las Escrituras, pero debemos preguntarnos qué significa "oráculo" en latín cristiano, en especial por la referencia, en el texto que nos ocupa, a "doctrina". En un principio, el término oráculo denominó un tipo de respuesta dada por una divinidad a un devoto, que buscaba orientación en su vida, en un templo (Delfos u Olimpia, entre tantos otros); fue también un ámbito de profecías, como nos legó Virgilio. Por influencia grecolatina, a partir del siglo II a. C., comienza una tradición oracular judía, es decir, en época intertestamentaria. ${ }^{22}$ La recepción de la tradición oracular por parte del cristianismo es sumamente compleja y se encuentra estrechamente vinculada a la historia de sus orígenes, especialmente ligada al gnosticismo de cuño cristiano. Respecto de la mención que hace san Agustín, debemos señalar que "oráculo" significa "doctrina religiosa" y que "los profanos" son simplemente aquellos que desconocen dicha doctrina o que no creen en su origen divino. Evidentemente, llega al Hiponense como un significado difuso, aunque claramente ligado a religiones o experiencias iniciáticas, que, en cuanto tales, no se corresponderían con las características de un texto que exhorta a la vida filosófica.

La segunda parte de la dedicatoria exhortativa busca poner en evidencia que las ocupaciones públicas de Romaniano y el consecuente reconocimiento social no lo hacen más feliz, sino que lo muestran abrumado por las preocupaciones de esas responsabilidades; la acción contraria de la fortuna, es decir, los reveses judiciales que san Agustín presenta como un instrumento de la Providencia han puesto las cosas en su lugar: la realidad humana es frágil y calamitosa (Acad. 1, 2: plena calamitatum). ${ }^{23}$ Es la propia vida la que enseña a Romaniano, no requiere ejemplos externos. "Despierta, despierta, te ruego" (Acad. 1, 3: Evigila, evigila, oro te). La Providencia, entonces, lo ha puesto en apuros para que muestre lo mejor de su carácter: si en la prosperidad material fue más liberal que rico, más justo que poderoso $($ Acad. 1,3$)$, ahora podrá mostrar su mejor versión o pasaje del sueño a la vigilia. El dispositivo retórico de persuasión culmina en el propio san Agustín, quien aduce su experiencia en este camino al despertar: también él fue tentado gravemente por la pompa del mundo, pero un dolor de pecho lo obligó a dejar la charlatanería (Acad. 1,3: ventosam professionem), y, más aún, fue tentado por la superstición, que, en san Agustín, tiene uso metonímico por "maniqueísmo": la filosofía (bajo la denominación general, pero significativa de Libri platonicorum) le permitió superar la parálisis intelectual y psicológica producida por el abandono del maniqueísmo.

\section{La dedicatoria del libro II $(2,1-9)$}

La segunda exhortación, la que abre el libro II, es más extensa y compleja, pues está elaborada como un anticipo de la discusión con los académicos. En ella, distinguimos tres partes. La exhortación a alcanzar la sabiduría en el contexto de la disputa con el escepticismo académico (2, 1-2, 2). San Agustín recuerda los beneficios recibidos por Romaniano desde la adolescencia de ambos y ahora quiere retribuírselos,

22 Francisco García Bazán, Introducción a Oráculos caldeos: Fragmentos y testimonios, de Numenio de Apamea (Madrid: Gredos, 1991), 9-10.

23 Giovanni Catapano, Il concetto di filosofia nei primi scritti di Agostino: Analisi dei passi metafilosofici dal Contra Academicos al De vera religione (Roma: Institutum Patristicum Agustinianum, 2001), 313-314. 
sosteniéndolo intelectualmente en la búsqueda de la vida filosófica (2,3-2, 7). Por ello, la primera parte de este apartado está dedicado a plantear las dificultades de la vida de estudio e investigación $(2,3)$. Y la búsqueda de la belleza (filocalia) e indagación de la sabiduría (filosofía) como nombres diversos de una misma actitud vital $(2,6-2,9)$. En la primera parte, san Agustín comienza una nueva exhortación acerca de la posibilidad de conocer, y en correlación con ello, si hay sabiduría en el sabio o, más gravemente, si existe la posibilidad de encontrar un hombre que merezca este calificativo. Por esto, anima a Romaniano a dedicarse a esta vida, aunque los bretes para perseverar en el estudio y en la ciencia sean múltiples: no solo el escepticismo del que se ocupa el diálogo, sino también las inclinaciones negativas de la naturaleza humana (pereza o simplemente falta de condiciones para la tarea), pasando por las dificultades propias de la vida del saber. La finalidad de esta primera parte de la exhortación es que Romaniano esté prevenido de lo que san Agustín denomina decepción ante las dificultades de encontrar la verdad; en latín agustiniano, simplemente desperatione inveniendi $(2,1)$. Luego, retoma esta idea con metáforas neoplatónicas sobre el conocimiento: la luz inteligible no brilla con la misma intensidad que el sol sensible o bien que los ojos interiores (mentibus) pueden entorpecerse más fácilmente que los exteriores (en 2, 1, san Agustín opone los conceptos mens y oculis). Tan nocivo como no tener esperanza de encontrar resulta la certeza de haber conocido, es decir, un modo de conocer que, en su limitación, considera que no es posible seguir avanzando. La conclusión de san Agustín: "la ciencia es una rara prerrogativa de unos pocos" (acad. 2, 1: ut scientia raro paucisque proveniat).

Con la naturalidad que le daba su frecuentación de textos neoplatónicos, san Agustín entrecruza las líneas de la filosofía y de la religiosidad, pues el estudio de la filosofía está presentado como una forma de devoción (acad. 2, 1: devotione ac pietate implorandum est). Por ello, el Hiponense eleva plegarias para que Romaniano sea liberado de sus ocupaciones cotidianas y de sus debilidades (acad. 2, 2: te cupio liberari); sin embargo, el fin del estudio no se alcanza solo con preces (votis), sino fundamentalmente con el esfuerzo de la voluntad (voluntate). Es importante notar, en este sentido, que el término para denominar aquello que pone en movimiento la voluntad es mentis (acad. 2, 2). En segunda parte mencionada, san Agustín enumera los favores recibidos por Romaniano y su preocupación por corresponder a la naturaleza de la amistad, no solo lo ayudó con los recursos de su fortuna, sino que también estuvo próximo con la palabra justa y amical: "Cuando quedé huérfano, me consolaste con tu amistad, me animaste con tus exhortaciones, me ayudaste con tus riquezas" (Acad. 2, 3). San Agustín intenta ahora devolver con creces los muchos favores de Romaniano, que le posibilitaron continuar sus estudios en Cartago y luego dedicarse a su vocación por el saber (Acad. 2, 3); en efecto, ahora que, gracias a la liberalidad de su amigo, puede gozar del ocio (Acad. 2, 4), desea liberarlo y, con este fin, se pone como ejemplo para que lo imite regresando a sí mismo: "he regresado a mí" (Acad. 2, 4: redeo ad me). Este pedido se fundamenta en que ambos habían considerado fundar un espacio de vida filosófica, especialmente cuando tuvieron acceso a la lectura de textos neoplatónicos: libri quidam pleni, "unos libros henchidos de sentido" $(2,5)$; con seguridad, son los mismos textos a los que se refiere en conf. 7, 13 (quidam Platonicorum libri) y que, tal vez en parte, coincidan con aquellos que menciona en beata v. 1, 4: Plotini paucissimi libri. Estos libros lo alejaron de las preocupaciones solo mundanas y lo condujeron a la conversión definitiva; de hecho, este relato finaliza con una versión breve de la famosa escena del jardín de Milán (conf. 8, 28 ss.).

La búsqueda de la belleza (filocalia) e indagación de la sabiduría (filosofía), es decir, la parte tres, nos conduce tal vez a la apropiación más profunda del neoplatonismo en perspectiva cristiana (no afecta a este análisis la fuerte postura crítica del propio san Agustín, sobre este pasaje, en retr. 1. 3.). A partir de la mención del episodio de la conversión en Milán, en que culminan los distintos momentos de este proceso, san Agustín alcanza un nuevo acceso a la comprensión de la filosofía: "rociado por esta luz difusa (id est, 
de su conversión) se me presentó de tal modo el semblante de la filosofía" (Acad. 2, 6). La transformación religiosa de san Agustín le muestra el camino de la filosofía, cuya característica central es la belleza o pulchritudo, que hace olvidar todo lo mundano (convites, jardines, termas, banquetes, bailarines, figuras todas que expresan sensualidad, riquezas, poder; 2, 6) y enciende, platónicamente, el deseo de su casta posesión, como un amante tierno y puro (Acad. 2, 6: blandus amatot et castus). Sin embargo, lo mundano no ciega de manera completa la belleza absoluta, porque también aquel posee cierta dignidad (decus) que no necesariamente cierra el camino a la contemplación. ¿Cuál es el camino por el cual lo bello o, mejor dicho, el amor de lo bello puede conducir al amor a la sabiduría? En principio, la presencia de la belleza parece llevar a un cierto grado de trascendencia, por el que avanza, a través de un camino sin interrupción, desde lo mundano a lo supramundano, ello implica que posee una dimensión absoluta, que incluye y requiere la verdad y el bien. Contiene, entonces, la dimensión religiosa o respuesta última del hombre a las preguntas sobre el mundo y sobre Dios; en este sentido, es comprensible la distancia que toma, en sus últimos años, san Agustín sobre el modo de ordenar la continuidad entre inmanencia y trascendencia, pues la belleza, en un sentido más profundo que la metafísica y la ética, tiende a una transfiguración inmanente del mundo: la manifestación de la belleza cósmica puede transformarse en un absoluto. San Agustín considera, por el contrario, que el espíritu que irradia la pulchritudo, desde el interior de las cosas, alcanza un poder configurador más elevado, alberga en sí a Dios, sin afectar su indiscutible autonomía. Cuando afirmamos que la belleza implica un designio ético, decimos que la existencia humana también queda incluida en ella, pues hemos visto que la perspectiva agustiniana de sabiduría, de clara raigambre clásica, se encuentra toda ella en cómo vivimos. San Agustín lo expresa en los términos de una fábula (Acad. 2, 7): filocalia y filosofía son hermanas, pero la primera perdió el cielo por su apego al placer (Acad. 2, 7). La filosofía, su hermana, se mueve con libertad, y muchas veces la reconoce, aunque la encuentre viviendo miserable y rastreramente; filocalia, por el contrario, no la reconoce, pues ha perdido conciencia de su origen (Acad. 2, 7). Esta fábula concierne al tema platónico y neoplatónico, que perfectamente se correlaciona con el cristianismo (Lc. 11, 34; Mt. 6, 22), según el cual es necesario un camino de ascesis para tener una experiencia "de la realidad verdadera" (Acad. 2, 7: Ergo ille, si veram pulchritudinem cuius falsae amator est, sanatis renudatisque paululum oculis posset intueri, quanta voluptate philosophiae gremio se involveret?). Si, para san Agustín, la fábula es "la voz de la filosofía", un acceso inferior al que proporciona su imagen o "rostro" (Acad. 2, 7: vox ipsius philosophiae), esta puede modificar el modo de vida; por ello, el ejemplo del hijo de Romaniano, Licencio, resulta más efectivo aún: el joven ha comenzado a filosofar y el maestro lo conduce primero por las artes liberales, a las que considera un verdadero propedéutico ("para que se yerga más firme y vigoroso"; Acad. $2,8)$. Romaniano tiene un buen dominio de estas artes y excelente disposición natural, por lo que solo requiere un ambiente de mayor libertad o de aire puro (Acad.2, 8: auras tibi liberas tantum opto), es decir, alejado del aire viciado de la vida pública y de los negocios. En consideración a su excelente disposición natural y su formación en las artes liberales, Romaniano debe superar dos escollos, que san Agustín había ya enunciado en la exhortación del libro I: que la presión del escepticismo académico no lo lleve a la desesperación de poder encontrar la verdad y que no presuma de haber alcanzado la verdad de una manera definitiva, pues se llega a ella con esfuerzo y mediante pequeños pasos (Acad. 2, 8-9). 


\section{Conclusiones}

En Contra los académicos, el primero de los diálogos que brota de la experiencia del retiro de Casiciaco, san Agustín realiza dos exhortaciones a la filosofía, que tienen el mismo destinatario, su amigo y mecenas Romaniano. El contexto biográfico e intelectual de san Agustín es sumamente complejo: la ruptura con el maniqueísmo implicó desasosiego y, por ello, la necesidad de encontrar respuestas a las dudas que lo habían alejado de la doctrina de Mani; entre ellas, la pérdida de certezas lo había conducido a desconfiar de la capacidad humana de conocer, circunstancia en la que volvió sobre sus lecturas de Cicerón y el escepticismo de la academia. En el proceso de su conversión y luego de ella, el vallado del escepticismo, que hacía imposible pasar de la sensación al conocimiento, bloqueaba también un acceso coherente al creer de la fe. En la revisión que hace de su vastísima obra pocos años antes de morir, san Agustín todavía sostenía que el cometido principal fue, sin duda, remover los obstáculos que impedían dar crédito a la razón y su conocimiento del mundo natural.

En este contexto, hace el llamado a Romaniano a la vida filosófica, quien había ingresado definitivamente al maniqueísmo por el fervoroso proselitismo de san Agustín en Tagaste. Siguiendo la estructura general de las distintas filosofías de cuño helenístico que no proponían una explicación solo racional del universo, el Hiponense no desvincula, sino que, por el contrario, considera una natural continuidad entre filosofía y teología. Este punto es inseparable de la formulación agustiniana del tema del alma y sus vínculos con el cuerpo, pues en todo momento se trata de clamar que el alma despierte para que pueda navegar hacia el puerto seguro de la filosofía: no puede ser conducida, sino que debe amar el viaje a través del mar proceloso de la incertidumbre. Esta metáfora marítima significa, para Romaniano, abandonar el mundo de sus responsabilidades sociales y consagrarse al ocio, es decir, a la paz de la contemplación en comunidad. En un diálogo que busca consolidar el sustento teórico del conocer humano, san Agustín toma distancia del escepticismo y del dogmatismo, pues argumenta tanto contra la postura escéptica, o desesperación de encontrar la verdad, como el dogmatismo o la seguridad de haber encontrado definitivamente la verdad. De hecho, san Agustín señala la dificultad de dar por cierto un conocimiento y, por ello, no descarta el escepticismo, sino que lo incorpora como la fase inicial del conocer y como antídoto contra la ingenuidad de dar a la facultad humana de conocer humano un alcance absoluto. En la perspectiva de este equilibrio, san Agustín exhorta a Romaniano a terminar de decidirse por llevar una vida filosófica. Con la preocupación de que la belleza trascendente, a la que conduce la Revelación, quede limitada a la belleza sensible, san Agustín tomó distancia de la correlación entre filocalia y filosofía; sin embargo, la formación del joven profesor en artes liberales estaba lejos de conducirlo a una actitud estética solo inmanente.

San Agustín integra en la exhortación a la filosofía el camino de la belleza; esta marca agustiniana da a la fe cristiana su hondura y su riesgo: solo es posible acceder a la belleza espiritual transitando por la belleza del cosmos, pero es propio del cosmos permanecer en el claroscuro que conduce a la pregunta acerca de la belleza que irradia en su propio esplendor. De este modo, el alma del que contempla, que se compadece con lo contemplado, alcanza el camino ascensional de su purificación. Para el anciano Agustín de las Retractaciones, la pulchritudo, por el contrario, puede ser una trampa o una prisión para la mirada desprovista de profundidad. 


\section{Bibliografía}

Agostino. Tutti i dialoghi. Introducción general, presentaciones de diálogos y notas de Giovanni Catapano. Milán: Bompiani, 2019.

Anoz, José. “Cronología de la producción agustiniana”. Augustinus 47, no. 186-187 (2002): 229-312.

Apamea, Numenio de. Oráculos caldeos: Fragmentos y testimonios. Introducción, traducciones y notas de Francisco García Bazán. Madrid: Gredos, 1991.

Augustín. Contra academicos (uel de Academicis). Introducción y comentarios de Therese Fuhrer. Berlín: De Gruyter, 1997.

Bassols de Climent, Mariano. Sintaxis histórica de la lengua latina. Madrid: Consejo Superior de Investigaciones Científicas, 1948.

Brachtendorf, Johannes. "Augustinus und der philosophische Weisheitsbegriff". En Die christlich-philosophischen Diskurse der Spätantike: Texte, Personen, Institutionen. Editado por Therese Fuhrer, 261-274. Stuttgart: Franz Steiner Verlag, 2008.

Brown, Peter. Augustine of Hippo: A Biography. Berkeley: University of California Press, 2000.

Catapano, Giovanni. L'idea di filosofia in Agostino. Padua: Il Poligrafo, 2000.

Catapano, Giovanni. Il concetto di filosofia nei primi scritti di Agostino: Analisi dei passi metafilosofici dal Contra academicos al De vera religione. Roma: Institutum Patristicum Agustinianum, 2001.

Catapano, Giovanni. “Quale scetticismo viene criticato da Agostino nel Contra academicos?”. Quaestio 6 (2006): 1-13. https://doi.org/10.1484/J.QUAESTIO.1.100060.

Decret, François. Aspects du manichéisme dans l'Afrique romaine: Les controverses de Fortunatus, Faustus et Felix avec saint Augustin. París: Études augustiniennes et CNRS, 1970.

Ernout, Alfred y François Thomas. Syntaxe latine. París: Éditions Klincksieck, 1964.

Gaffiot, Félix. Dictionnaire latin-français. París: Hachette, 1934.

Foley, Michael P. "Cicero, Augustine, and the philosophical roots of the Cassiciacum dialogues". Revue d'Etudes Augustiniennes et Patristiques 45, no. 1 (1999): 51-77. https://doi.org/10.1484/J.REA.5.104795.

Goutierre, Marie-Dominique. "La importancia del fin, causa de las causas: Hacia una teología viva y contemplativa en la escuela de santo Tomás". Scripta Theologica 41, 2 no. (2009): 351-375. https://dadun.unav.edu/ handle/10171/11488.

Grant, Edward. "Science and Theology in the Middle Ages". En God and Nature: Historical Essays on the Encounter between Christianity and Science. Editado por David C. Lindberg y Ronald L. Numbers, 49-75. Berkeley: University of California Press, 1986. https://doi.org/10.1525/9780520908031-004

Hadot, Pierre. Exercices spirituels et philosophie Antique. París: Éditions Albin Michel, 2003.

Libera, Alain de. Albert le Grand et la philosophie. París: J. Vrin, 1990.

Mendoza, José María Felipe. “Tomás de Aquino y la relación entre filosofía y teología: Una interpretación literal de la Suma de Teología I, q. 1, a. 1”. Universitas Philosophica 35, no. 70 (2018): 131-149. https://doi.org/10.11144/ javeriana.uph35-70.arft.

Moreschini, Claudio. Storia del pensiero cristiano tardo-antico. Milán: Bompiani, 2013.

Navarro Coma, Francesc. "Amistad e intereses entre un curial rico y un curial pobre". Polis: Revista de Ideas y Formas Políticas de la Antigüedad Clásica 10 (1998): 247-267.

Perler, Othmar. Les voyages de saint Augustin. París: Études Augustiniennes, 1969.

Unger Parra, Biviana. "Agustín y Cicerón: La búsqueda de la verdad”. Universitas Philosophica 33, no. 67 (2016): 201-215. https://doi.org/10.11144/Javeriana.uph33-67.acbv.

Voss, Bernd Reiner. Der Dialog in der frühchristlichen Literatur. Múnich: Wilhelm Fink Verlag, 1970. 